\title{
HUBUNGAN ANTAR UKURAN BEBERAPA BAGIAN TUBUH RAJUNGAN (PORTUNUS PELAGICUS) DI PERAIRAN UTARA LAMONGAN, JAWA TIMUR
}

\author{
Muhammad Arif Rahman $^{\text {a,b,*, }}$, Feni Iranawati ${ }^{\text {a, b }}$, Eko Sulkhani Yulianto ${ }^{\text {a,c }}$, Sunardi ${ }^{\text {a,c }}$ \\ ${ }^{a}$ Fakultas Perikanan dan Ilmu Kelautan, Universitas Brawijaya, ${ }^{b}$ MEXMA Research Group, FPIK Universitas \\ Brawijaya, Malang, Indonesia, ${ }^{c}$ IMFISHER Research Group, FPIK Universitas Brawijaya, Indonesia \\ *Koresponden penulis : arifelzain@ub.ac.id
}

\begin{abstract}
Abstrak
Rajungan (portunus pelagicus) merupakan salah satu komoditas penting perikanan Indonesia. Pengetahuan tentang aspek biologi rajungan, termasuk hubungan antar ukuran bagian-bagian tubuhnya (morfometrik) dan sebaran lebar karapas serta beratnya, akan berguna sebagai salah satu informasi dalam pengelolaan rajungan. Penelitian ini bertujuan untuk mengetahui hubungan lebar karapas-berat rajungan, hubungan lebar-panjang-tinggi karapas, serta sebaran lebar dan berat rajungan. Metode yang digunakan adalah survei dengan pengambilan sample secara acak pada 2 (dua) titik pendaratan ikan di perairan utara Lamongan, khusunya kecamatan Paciran pada bulan Juli sampai September 2018. Hasil penelitian menunjukkan sifat pertumbuhan isometrik untuk rajungan betina dan allometrik positif untuk rajungan jantan. Selain itu, didapatkan hubungan linear positif dengan nilai $a=0,06$ dan $b=0,45$ untuk lebar-panjang karapas serta nilai $\mathrm{a}=0,06$ dan $\mathrm{b}=0,25$ untuk lebar-tinggi karapas. Rajungan betina paling banyak ditangkap pada lebar karapas $12-13 \mathrm{~cm}$ dan berat $100 \mathrm{~g}$, sedangkan rajungan jantan sering ditangkap dengan lebar karapas $11 \mathrm{~cm}$ dan berat $80-90 \mathrm{~g}$. Masih adanya rajungan dibawah ukuran lebar karapas $10 \mathrm{~cm}$ yang tertangkap (lebar karapas diatas $10 \mathrm{~cm}$ adalah aturan rajungan yang boleh ditangkap sesuai dengan PER MEN KP 56/2016), maka informasi tentang hubungan lebar-panjang-tinggi rajungan dapat dijadikan masukan untuk melakukan modifikasi alat tangkap, misalnya mendesain ukuran celah pelolosan pada bubu, agar rajungan dengan lebar karapas dibawah $10 \mathrm{~cm}$ dapat keluar dari alat tangkap.
\end{abstract}

Kata Kunci: hubungan lebar karapas-berat, krustasea, morfometri

\begin{abstract}
Blue swimming crab (Portunus pelagicus) is one of the important fisheries commodities in Indonesia. information of its biological aspects, such as relationship between size of body parts (morphometric) and size distribution of its carapace width and weight, will be useful for managing the crab fishery. The aims of this study are to determine relationship between carapace width-weight, relationship between carapace width-length-height, and size distribution of carapace length and weight the crab. The method used was a survey with random sampling at 2 (two) fish landing in the northern waters of Lamongan, especially Paciran sub-district from July to September 2018. The study found that growth pattern of female and male crabs was isometric and allometric positive, respectively. In addition, a positive linear relationship was obtained with $a=0.06$ and $b=0.45$ for carapace width-length and $a=0.06$ and $b=0.25$ for the carapace width-height. The female crab was mostly captured in size $12-13 \mathrm{~cm}$ of carapace width and $100 \mathrm{~g}$ of weight, while the male crab was often captured in size $11 \mathrm{~cm}$ of carapace width and 80-90 g of weight. Catches consisted of some crabs with the size below $10 \mathrm{~cm}$ of carapace width (carapace width above $10 \mathrm{~cm}$ is a legal size of crab's catch in accordance with the Ministerial decree of marine affairs and fisheries number 56/2016), therefore, the information about the width-length-height relationship of the crab can be used to modify fishing gears, for example designing the size of the escape gap on traps, to allow the crabs with the size below $10 \mathrm{~cm}$ of carapace width escape from fishing gear.
\end{abstract}

Keywords: carapace width-weight relationship, crustacea, morphometric

\section{PENDAHULUAN}

Rajungan (Portunus pelagicus) merupakan salah satu jenis rajungan yang paling sering ditangkap oleh nelayan di Indonesia [1] [2] [3]. Bersama dengan jenis rajungan yang lain serta kepiting, kelompok krustasea ini menjadi salah satu komoditas 
perikanan dengan peluang eksport yang menggiurkan, dimana dari tahun 2012-2017 nilai eksportnya rata-rata naik sekitar $6,15 \%$ [4].

Tahun 2014, Jawa Timur menjadi provinsi ke-enam penghasil rajungan terbanyak di Indonesia dengan volume produksi mencapai 3.510 ton, dari penangkapan di perairan Utara dan Selatan Jawa Timur [5]. Pada tahun 2015, kabupaten Lamongan merupakan penyumbang produksi rajungan ke-tiga terbesar di Jawa Timur setelah kabupaten Banyuwangi dan Bangkalan, dengan proporsi $14,2 \%$ dari total produksi rajungan Jawa Timur [6].

Namun, tren Catch per Unit Effort (CpUE) sumberdaya rajungan di WPP 712, dimana Jawa Timur juga termasuk didalamnya, telah mengalami penurunan [7], serta status pemanfaatan rajungan cenderung overfisihng pada beberapa wilayah Jawa Timur seperti Bangkalan [8] dan Tuban [9] membuat pengelolaan rajungan di Jawa Timur perlu dilakukan untuk menjamin sumberdaya ini tetap berkelanjutan.

Pengelolaan suatu sumberdaya membutuhkan berbagai informasi yang berkaitan dengan sumberdaya tersebut, salah satu adalah kajian populasi [10]. Dalam kajian populasi, informasi tentang ukuran bagianbagian tertentu (morfometri) dari tubuh individu, seperti panjang-berat-lebar, serta hubungan antar ukuran tersebut dapat memberikan informasi penting tentang populasi suatu sumberdaya, termasuk jumlah dan seberapa sehat populasi tersebut [11].

Berdasarkan latar belakang diatas, penelitian ini bertujuan untuk melakukan estimasi beberapa aspek biologi rajungan, terutama hubungan lebar karapas-berat rajungan, hubungan lebar-panjang-tinggi karapas, serta sebaran lebar dan berat rajungan. Hasil penelitian ini diharapkan dapat memberi gambaran tentang kondisi rajungan di perairan Lamongan, serta informasi awal dalam modifikasi alat penangkap rajungan yang lebih selektif dalam ukuran rajungan.

\section{METODE PENELITIAN}

\section{Pengambilan data}

Penelitian ini dilaksanakan pada tempat pendaratan ikan di wilayah perairan utara Lamongan dari bulan Juli sampai September 2018. Pengambilan data dilakukan secara acak oleh enumerator dengan melakukan pengukuran rajungan di tempat pedagang (pengepul) dimana nelayan menjual rajungan hasil tangkapannya.

Pengukuran panjang-lebar-tinggi karapas (Gambar 1) dilakukan menggunakan jangka sorong dengan ketelitian 0,01 mm, sedangkan berat rajungan ditimbang menggunakan timbangan digital dengan ketelitian $0,1 \mathrm{~g}$. Selain itu, enumerator juga mengamati jenis kelamin rajungan dari abdomennya (Gambar 2). Adapun jumlah sample yang didapatkan selama pengambilan data sebanyak 5684 (jantan sebanyak 3482 ekor dan betina 2202 ekor) untuk pengamatan hubungan lebar karapas-berat serta sebarannya. Sedangkan, untuk pengamatan hubungan lebar-panjang-tinggi menggunakan sample sebanyak 812 ekor.

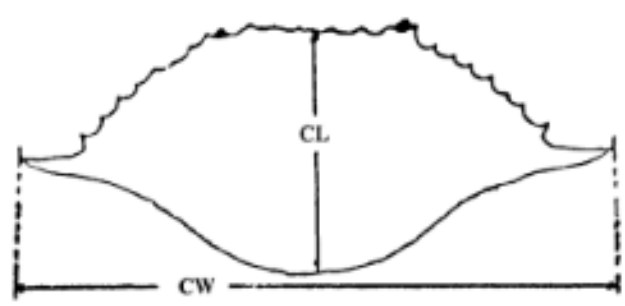

Gambar 1. Pengukuran karapas rajungan, $\mathrm{CW}=$ lebar karapas; $\mathrm{CL}=$ panjang karapas [11]

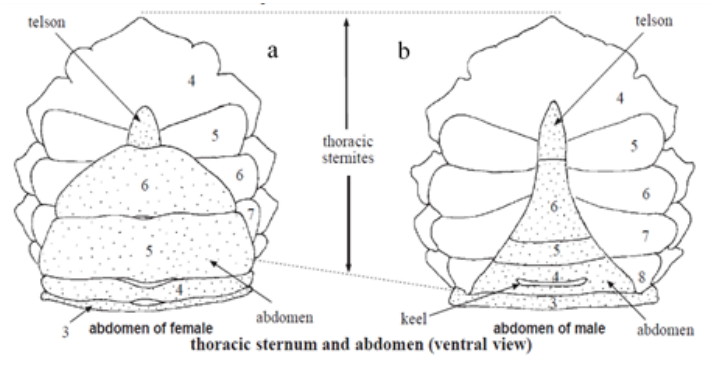

Gambar 2. Bentuk abdomen betina (a) dan jantan (b) [12] 


\section{Metode Analisis}

Hubungan panjang-berat dianalisa menggunakan persamaan pertumbuhan allometris [13];

$\mathrm{W}=\mathrm{aL}^{\mathrm{b}}$

Dimana

$\mathrm{W} \quad=$ berat tubuh $(\mathrm{g})$

$\mathrm{L} \quad=$ lebar karapas $(\mathrm{cm})$

$\mathrm{a}$ dan $\mathrm{b}=$ konstanta hasil regresi

Saat nilai $\mathrm{b}=3$, maka dapat dikatakan hubungan yang terbentuk bersifat isometrik, dimana bertambahnya lebar karapas seimbang dengan bertambahnya berat rajungan. Sebaliknya, bila nilai $b \neq 3$, maka hubungannya adalah allometris, dimana pertambahan lebar karapas tidak sebanding dengan berat rajungan. Penentuan nilai $b$ tersebut kemudian dapat diuji dengan uji $\mathrm{t}$ [14].

Analisis hubungan lebar dengan tinggi dan panjang karapas dilakukan dengan metode regresi linear sederhana dengan persamaan;

$\mathrm{Y}=\mathrm{a}+\mathrm{bX}$

Dimana

$\mathrm{Y}=$ panjang/tinggi karapas $(\mathrm{cm})$

$\mathrm{X}=$ Lebar karapas $(\mathrm{cm})$

a $=$ intersep

$\mathrm{b}=$ slope

Sementara itu, sebaran lebar karapas dan berat rajungan dijelaskan menggunakan analisis deskriptif, dimana analisis ini dapat memberikan gambaran tentang kondisi suatu objek yang diteliti [15]. Penggunaan metode ini adalah dengan membuat selang kelas lebar karapas dan berat rajungan kemudian melakukan perhitungan frekuensi pada masing-masing selang kelas.

\section{HASIL DAN PEMBAHASAN}

\section{Hubungan lebar karapas dan berat}

Sifat pertumbuhan rajungan dapat digambarkan dari hubungan lebar karapas dan beratnya. Setelah dilakukan analysis dengan uji-t dengan selang kepercayaan 95\%, didapatkan hasil rajungan betina memiliki sifat pertumbuhan isometrik sedangkan rajungan jantan pertumbuhannya bersifat allometrik (Gambar 3). Pertumbuhan rajungan jantan masuk dalam kategori allometrik positif $(b>3)$ atau dengan kata lain rajungan jantan di perairan utara kabupaten Lamongan cenderung gemuk [14].
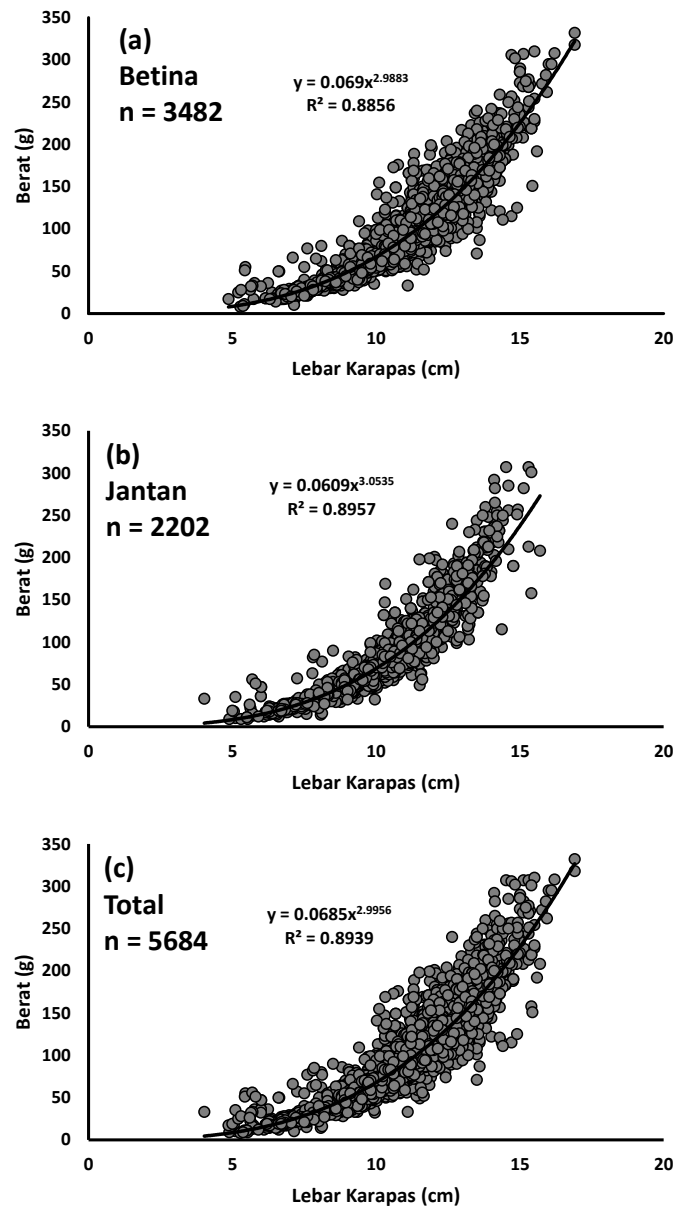

Gambar 3. Hubungan lebar karapas dengan berat rajungan jantan (a), betina (b), dan total (c)

Beberapa penelitian tentang panjangberat rajungan di berbagai perairan Indonesia memiliki variasi hasil sifat pertumbuhan. Pada perairan Labuhan Maringgai, Lampung timur, 
sifat pertumbuhan rajungan jantan dan betina secara berurutan adalah isometrik dan allometrik positif [16]. Sementara itu, pada beberapa wilayah di perairan laut utara Jawa (Jakarta, Cirebon, Demak, Rembang dan Sumenep) juga didapatkan hasil yang berbeda untuk sifat pertumbuhan rajungan jantan dan betina [17]. Selanjutnya, pada perairan Lamongan, Tuban dan Pasuruan didapatkan sifat pertumbuhan allometrik negatif untuk rajungan jantan maupun betina [18]. Variasi sifat pertumbuhan tersebut dapat dipengaruhi oleh beberapa faktor, antara lain jenis kelamin, suhu, salinitas, makanan dan proses reproduksi [10].
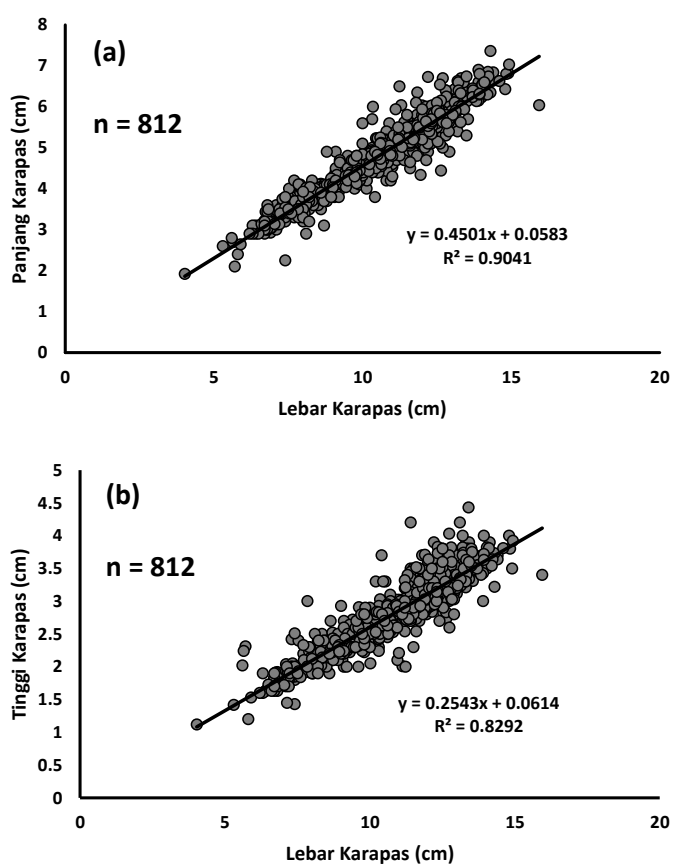

Gambar 4. Hubungan antara lebar dan panjang karapas rajungan (a); hubungan antara lebar dan tinggi karapas (b)

\section{Hubungan lebar karapas dengan panjang dan tinggi karapas}

Hubungan antara lebar dengan panjang maupun tinggi karapas diekspresikan sebagai hubungan linear (Gambar 4). Hasil regresi menunjukkan bahwa secara signifikan terdapat hubungan linear positif antara panjang dan lebar karapas rajungan $(\mathrm{F}=7635,96 ;$ df 1,$810 ; \mathrm{P}<0,001)$ serta antara tinggi dan lebar karapas $(\mathrm{F}=3932,23$; df 1,810;
$\mathrm{P}<0,001)$. Penambahan panjang karapas adalah sebesar $0,45 \mathrm{~cm}$ setiap penambahan 1 $\mathrm{cm}$ lebar karapas, sedangkan setiap penambahan lebar karapas sebanyak $1 \mathrm{~cm}$, tinggi karapas akan bertambah sebesar 0,25 $\mathrm{cm}$.

Sejak tahun 2015, pemanfaatan sumberdaya rajungan telah diatur oleh pemerintah melalui PER MEN KP No. 1/2015 yang kemudian diganti dengan PER MEN KP No. 56/2016. Dalam PER MEN KP tersebut terdapat aturan bahwa rajungan boleh ditangkap apabila tidak bertelur dan memiliki lebar karapas diatas $10 \mathrm{~cm}$ atau berat 60 gram. Informasi hubungan lebar-panjang karapas serta lebar-tinggi karapas dapat digunakan untuk mencari panjang dan tinggi karapas rajungan dengan ukuran yang boleh untuk ditangkap (diatas $10 \mathrm{~cm}$ ). Hal ini akan bermanfaat dalam modifikasi bagian-bagian tertentu dari alat penangkap rajungan, misalnya penentuan dimensi celah pelolosan (escape gap) pada alat tangkap bubu (perangkap) [19] dengan harapan rajungan berukuran dibawah $10 \mathrm{~cm}$ akan dapat lolos dari bubu.

\section{Sebaran lebar karapas dan berat rajungan}

Rajungan betina memiki rata-rata ukuran yang lebih besar daripada rajungan jantan (Tabel 1). Melihat sebaran lebar karapasnya, sebagian besar rajungan jantan yang tertangkap memiliki lebar karapas 11 $\mathrm{cm}$, sedangkan rajungan betina banyak tertangkap dengan lebar karapas 12-13 cm (Gambar 5). Selain itu, rajungan paling banyak ditangkap pada berat 80-90 g untuk rajungan jantan dan $100 \mathrm{~g}$ untuk rajungan betina (Gambar 6).

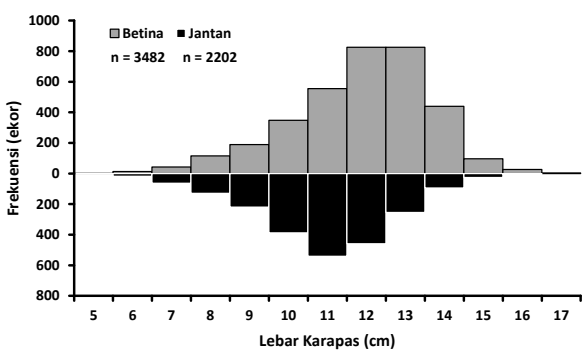

Gambar 5. Sebaran lebar karapas rajungan jantan dan betina 


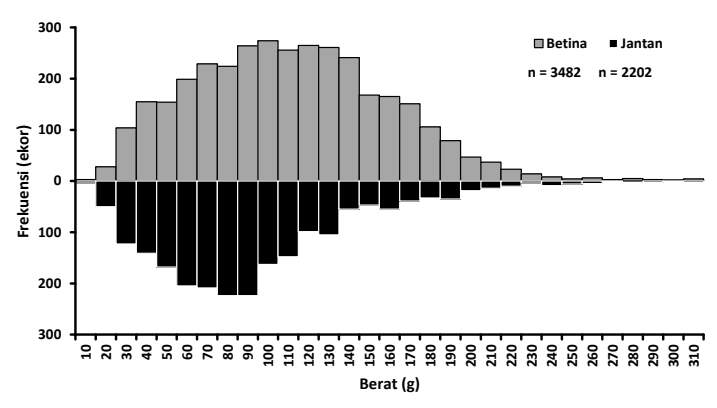

Gambar 6. Sebaran berat rajungan jantan dan betina

Hasil penelitian mendapatkan bahwa baik rajungan jantan maupun betina banyak ditangkap pada lebar karapas diatas $10 \mathrm{~cm}$ dan berat diatas $60 \mathrm{~g}$. Hal ini mengindikasikan bahwa sebagian besar hasil tangkapan rajungan oleh nelayan di perairan utara Lamongan telah sesuai dengan PER MEN KP No. 56/2016. Namun, dengan masih adanya rajungan dibawah ukuran lebar karapas $10 \mathrm{~cm}$ yang tertangkap, sekitar 27\% (Gambar 5), maka modifikasi alat tangkap dengan memberikan jalan bagi rajungan yang memiliki lebar karapas dibawah $10 \mathrm{~cm}$ untuk lolos layak dicoba.

Tabel 1. Ukuran beberapa bagian tubuh rajungan jantan dan betina

\begin{tabular}{lcccccc}
\hline \multicolumn{1}{c}{ Ukuran } & \multicolumn{3}{c}{ Jantan } & \multicolumn{3}{c}{ Betina } \\
& Minimal & Maksimal & Rata-rata \pm SE & Minimal & Maksimal & Rata-rata \pm SE \\
\hline Berat (g) & 9 & 307 & $87,12 \pm 1,01$ & 8 & 332 & $107,43 \pm 0,83$ \\
Lebar Karapas (cm) & 4,02 & 15,7 & $10,42 \pm 0,04$ & 4,86 & 16,9 & $11,38 \pm 0,03$ \\
Panjang Karapas (cm) & 1,92 & 6,84 & $4,65 \pm 0,05$ & 2,1 & 7,36 & $5,00 \pm 0,04$ \\
Tinggi Karapas (cm) & 1,12 & 4 & $2,63 \pm 0,03$ & 1,42 & 4,43 & $2,87 \pm 0,03$ \\
\hline
\end{tabular}

\section{KESIMPULAN}

Sifat pertumbuhan rajungan jantan dan betina di perairan utara Lamongan masingmasing adalah allometrik positif dan isometrik. Hubungan antara lebar-panjangtinggi karapas mendapatkan hubungan linear positif dengan nilai $\mathrm{a}=0,06$ dan $\mathrm{b}=0,45$ untuk lebar-panjang karapas, sedangkan untuk lebar-tinggi karapas didapatkan nilai a $=0,06$ dan $b=0,25$. Sementara itu, rajungan betina paling banyak ditangkap pada lebar karapas $12-13 \mathrm{~cm}$ dan berat $100 \mathrm{~g}$, sedangkan rajungan jantan sering ditangkap dengan lebar karapas $11 \mathrm{~cm}$ dan berat $80-90 \mathrm{~g}$.

\section{SARAN}

Perlu dilakukan penelitian pada bulan lainnya untuk mendapatkan gambaran tentang sifat pertumbuhan rajungan secara lebih menyeluruh. Selain itu, informasi tentang hubungan lebar-panjang-tinggi karapas dapat digunakan untuk membuat modifikasi alat tangkap sebagai upaya mengurangi tertangkapnya rajungan dengan ukuran yang belum semestinya untuk ditangkap.

\section{UCAPAN TERIMA KASIH}

Penelitian ini merupakan bagian dari penelitian yang didanai oleh program Hibah Peneliti Pemula Tahun 2018 yang diselenggarakan dan dibiayai oleh Universitas Brawijaya (UB) melalui Lembaga Penelitian dan Pengambian Masyarakat UB. Peneliti berterima kasih kepada semua pihak yang telah membantu dalam pelaksanaan penelitian ini.

\section{DAFTAR PUSTAKA}

[1] M. K. Moosa, Beberapa Catatan Mengenai Rajungan dari Teluk Jakarta dan Pulau-Pulau Seribu, Lembaga Oseanologi Nasional-Lembaga Ilmu Pengetahuan Indonesia, Jakarta. 1980.

[2] D. D Kembaren, T. Ernawati, Suprapto, "Biologi dan Parameter Populasi Rajungan (Portunus pelagicus) di 
Perairan Bone dan Sekitarnya", Jurnal Penelitian Perikanan Indonesia, 18(4), 273-281, 2012.

[3] Zairion, Y. Wardiatno, A. Fahrudin, "Sexual Maturity, Reproductive Pattern and Spawning Female Population of the Blue Swimming Crab Portunus pelagicus (Brachyura: Portunidae) in East Lampung Coastal Waters, Indonesia", Indian Journal of Science and Technology, 8(7), 596-607, 2015.

[4] Kementerian Kelautan dan Perikanan, "Materi Paparan Dirjen PDSPKP pada Forum Merdeka Barat 9 (FMB9)", https://kkp.go.id/wpcontent/uploads/2018/01/KKP-DirjenPDSPKP-FMB-Kominfo-19-Januari2018.pdf, 2018

[5] Direktorat Jenderal Perikanan Tangkap, Statistik Perikanan Tangkap Indonesia Menurut Provinsi Tahun 2014, Kementerian Kelautan dan Perikanan, Jakarta, 2015.

[6] Dinas Kelautan dan Perikanan Kabupaten Lamongan, Data Produksi Ikan Laut di Kabupaten Lamongan Tahun 2015, Lamongan, 2016.

[7] A. Budiarto, Pengelolaan perikanan rajungan dengan pendekatan ekosistem di perairan Laut Jawa (WPPNRI 712). Sekolah Pascasarjana, Institut Pertanian Bogor, Bogor, 2015.

[8] F. F Muhsoni, I. W. Abida, "Analisis Potensi Rajungan (Portunus pelagicus) di Perairan Bangkalan Madura", EMBRYO, 6(2), 140-147, 2009.

[9] T. A. Tama, D. Wijayanto, T. D. Hapsari, "Analisis Bioekonomi Sumberdaya Rajungan (Portunus pelagicus) di Kabupaten Tuban", Jurnal Perikanan Tangkap, 1(1), 26-34, 2017.

[10] T. Ernawati, M. Boer, Yonvitner, "Biologi Populasi Rajungan (Portunus pelagicus) di Perairan Sekitar Wilayah
Pati Jawa Tengah", BAWAL, 6(1), 3140, 2014.

[11] J. Josileen, "Morphometrics and lengthweight relationship in the blue swimming crab, Portunus pelagicus (Linnaeus, 1758) (decapoda, brachyura) from the Mandapam coast, India", Crustaceana, 84(14), 1665-1681, 2011.

[12] K. E. Carpenter, V. H. Niem, FAO Species Identification Guide for Fishery Purposes: The Living of Marine Resources of the Western Central Pacific Vol 2, Food and Agriculture Organization of the United Nations, Rome, 1998.

[13] M. King, Fisheries Biology, Assessment and Management $2^{\text {nd }}$ Edn, Blackwell Publishing, Iowa, 2007.

[14] D. Setyohadi, D. G. R. Wiadnya, Pengkajian Stok dan Dinamika Populasi Ikan Lemuru, Universitas Brawijaya Press, Malang, 2018.

[15] M. Nazir, Metode Penelitian, Ghalia Indonesia, Bogor, 2003.

[16] A. Damora, E. Nurdin, "Beberapa Aspek Biologi Rajungan (Portunus pelagicus) di Perairan Labuhan Maringgal Lampung Timur". BAWAL, 8(1), 13-20, 2016.

[17] T. Ernawati, B. Sumiono, H. Maduppa, "Reproductive ecology, spawning potential, and breeding season of blue swimming crab (Portunidae: Portunus pelagicus) in Java Sea, Indonesia", Biodiversity, 18(4), 1705-1713, 2017.

[18] L. Murni, D. Arfiati, A. Kurniawan, Y. Kilawati, H. U. Subarijanti, Suliswanto, M. N. A. Syams, A. B. Gumelar, A. R. A. Huda, "Biological analysis of blue swimming crab (Portunus pelagicus) from collectors in Lamongan, Tuban, Pasuruan, and Rembang, Java, Indonesia", Journal of Experimental Life Science, 8(2), 90-96, 2018. 
[19] E. Divinubun, Keragaan modifikasi perangkap lipat kepiting di desa Mayangan dan Legonwetan Subang, Jawa Barat, Sekolah Pascasarjana, Institut Pertanian Bogor, Bogor, 2012. 